\title{
Small Intestine Atresia
}

National Cancer Institute

\section{Source}

National Cancer Institute. Small Intestine Atresia. NCI Thesaurus. Code C98828.

A congenital malformation characterized by the absence of a normal opening in a part of the small intestine. 